\title{
Development of Fibre Reinforced Cementitious Composite for Ceiling Application
}

\author{
I.O. Oladele ${ }^{1}$, A.D. Akinwekomi ${ }^{1}$, S. Aribo ${ }^{1}$, and A.K. Aladenika ${ }^{2}$ \\ ${ }^{1}$ Department of Metallurgical and Materials Engineering, Federal University of Technology, \\ Akure, Ondo State, Nigeria. \\ ${ }^{2}$ Department of Science Laboratory Technology Rufus Giwa polytechnic Owo, Ondo State, \\ Nigeria \\ *Corresponding Author: wolesuccess2000@yahoo.com, akeemzy@yahoo.com
}

\begin{abstract}
Natural sponge fibre (Acanthus montanus) was used as reinforcement for ceiling materials in this research work. This fibre, being fairly strong and stiff as well as cheap and plentiful with low energy demand during manufacture, are strong contenders for the reinforcement of cementbased materials. The fibre, whose mass fraction was the variable in this work, was cut down into smaller sizes and mixed with pulverised waste paper, cement and water. The resulting slurry was then poured into rectangular moulds which were compacted until the excess water was expelled and resulting composites became hard. Demoulded samples were left to cure in the open laboratory air for 28 days. Flexural and water absorptivity tests were carried out on the various samples which showed that reinforcement and best mechanical properties were obtained at optimum fibre mass fraction of $4 \%$ when compared with the brittle matrix in the absence of reinforcement. These tests confirmed the possible use of sponge fibres as reinforcement in cement matrices for ceiling purposes.
\end{abstract}

Keywords: Natural sponge fibres, mass fraction, flexural test and water absorptivity test.

\section{INTRODUCTION}

The development and understanding of building materials has generally received less attention in the last few decades [1]. Probably one area where the building materials technology has been 
much neglected is in the realm of housing. The human habitat has become an almost intractable world problem, most especially in the Third World.

Natural organic fibres have a very important role in the alleviation of the housing problem. They not only occur in luxurious abundance in many parts of the world, but can also lead directly to energy savings, conservation of the world's most scarce resources and protect human and environment. Natural and vegetable plants and fibres have thus a unique irreplaceable role in the ecological cycle. Despite the fact that natural fibres generally have poor mechanical properties compared with synthetic fibres [2], their use as reinforcement material has been adopted by mankind to make straw reinforced huts and other articles [3]. Their natural abundance, plentiful supply, relative cheapness and swift replenishability are the strongest arguments to utilize them in the construction industry [1].

Cement and concrete matrices reinforced with short, discrete or long single/bundles of fibre present exciting and challenging new construction materials. The behaviour and properties of cement-based materials may be better understood, designed, and predicted using a modern approach than was possible on the basis of traditional concrete technology [4]. These materials belong to a group of brittle-matrix composites. The major role of fibres is in delaying and controlling the tensile cracking of the matrix. This controlled multiple cracking reduces deformation at all stress levels, and imparts a well-defined post-cracking and post-yield behaviour. The fracture toughness, ductility and energy absorption capacity of the composite are then substantially improved. These technical benefits can be utilized both in semi-structural elements such as thin sheets, flat sheets, corrugated and cladding panel as well as in load bearing members.

Therefore, the aim of this paper is to make use of natural sponge fibres for the production of ceiling board for the building industry.

\section{MATERIALS AND METHODS}

The materials required for this research work were all sourced locally. These included fibres from the stem of the natural sponge plant (Acanthus montanus), waste paper, wooden rectangular moulds, water, cellophane sheets and cement. The fibres from the natural sponge plant (Acanthus montanus) were cut down into a size range of $35-40 \mathrm{~mm}$. This was done to avoid balling problem during mixing and to facilitate homogeneous mixing of the composite.

The waste paper, which served as filler in this research work, was obtained from old newspaper pages. These were first cut down into smaller sizes and then soaked in water until they soften. Manual pounding using the mortar and pestle was used to pulverize them. The variable in this research work was fibre mass concentration. The recipe which was maintained constant was a mixture of cement and waste paper in the ratio 70:30 by weight. The total weight of matrix 
utilized was $500 \mathrm{~g}$. The fibre mass fractions, $\mathrm{M}_{f}$ aimed at were $\mathrm{M}_{f}=0,2,4,6,8$ and $10 \%$. This fibre mass fraction was defined as the ratio of fibres to the dry constituents of the matrix (cement and waste paper) by weight [5]. Table 1.0 below gives the matrix and fibre mass compositions utilized for this research work.

Table 1. Matrix and Fibre Mass Compositions.

\begin{tabular}{ccccc}
\hline $\begin{array}{l}\text { Fibre content }(\%) \\
\text { paper }(\mathrm{g})\end{array}$ & $\begin{array}{c}\text { weight of fibre }(\mathrm{g}) \\
\text { weight of matrix }(\mathrm{g})\end{array}$ & weight of cement $(\mathrm{g})$ & weight of waste \\
\hline 0 & 0 & 350 & 150 & 500 \\
2 & 10 & 350 & 150 & 500 \\
4 & 20 & 350 & 150 & 500 \\
6 & 40 & 350 & 150 & 500 \\
8 & 60 & 350 & 150 & 500 \\
10 & 80 & 350 & 150 & 500 \\
\end{tabular}

The weighed masses of pulverised paper, cement, fibre and water were mixed together until homogeneity was achieved. The optimum water/cement ratio for workable mixes was based on the formula proposed by Lasisi et al (1984),

$$
\mathrm{Y}=-0.9+3.85 \mathrm{X}
$$

where $\mathrm{Y}=$ cement/waste paper ratio

$\mathrm{X}=$ water/cement ratio

A slight modification was made to this formula to produce slurry with excess water to ensure its good flow. This enabled the composite to take on the shape of the mould cavity, giving it a smooth surface free of voids and air holes. This new formula which was utilized for this research work is as stated below

$$
Y=-0.9+0.9625 X
$$

Where $\mathrm{Y}$ and $\mathrm{X}$ still maintain their definitions.

The measured dry weights of the matrix and fibres were then mixed with the pre-determined volume of water until homogeneity was obtained. This was done for each of the mixes and fibre mass fraction. It was observed that balling problem began to become serious when a fibre mass fraction of $6 \%$ was included in the mix. 
After a homogeneous mixture was obtained, the slurry was poured into the rectangular moulds measuring $610 \mathrm{~mm} \times 80 \mathrm{~mm}$ with a height of $15 \mathrm{~mm}$ and labelled with the corresponding mass fraction. A 5-ton hydraulic jack was used in compressing the composites for one hour before the compacting pressure was removed. The composites were allowed to cure slowly for twenty- four hours before they were de-moulded. In all eighteen samples were produced, three for each mass faction. All the samples were allowed to cure in the open laboratory air for twenty-eight days before flexural and water absorptivity tests were conducted on them.

\subsection{Flexural Test}

Flexural test based on the three-point loading principle was carried out on each of the samples from which the flexural load, $F_{f}$ and strength, $\sigma_{f s}$ of each sample was obtained.

\subsection{Water Absorptivity Test}

This test quantifies the water absorptivity of the cement composite. Being a product to be used for ceiling purpose, this test becomes pertinent to measure its response to water leakages from the roof after or during a down-pour. Three samples were cut from each mass fraction, weighed and soaked in water for eight hours. Thereafter, they were removed from water, cleaned, dried, and re-weighed. The obtained data were recorded against each mass fraction and the mean obtained. The percentage water absorptivity was also calculated and recorded against each mass fraction.

\section{RESULTS AND DISCUSSION}

\subsection{Flexural Strength}

Figure 1 depicts the results graphically. Flexural Strength is the stress at fracture from a bend (or flexure) test. From the results, the sample with fibre mass fractions of $4 \%$ followed by $2 \%$ had the highest strengths of $1.352 \mathrm{MPa}$ and $1.342 \mathrm{MPa}$ respectively while fibre mass fractions of $6 \%$, $8 \%$ and $10 \%$ follow with decreasing strength values. The control sample with $0 \%$ fibre mass fraction had the lowest strength values of $0.979 \mathrm{MPa}, 0.894 \mathrm{MPa}$ and $0.690 \mathrm{MPa}$ respectively. 


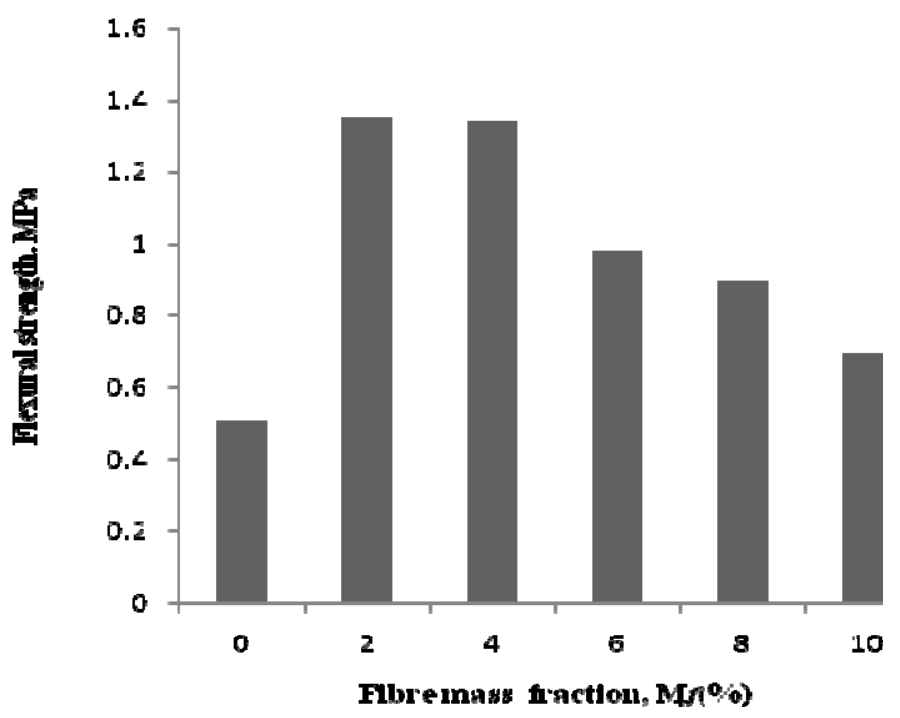

Figure 1: Plot of Flexural Strength against Fibre Mass Fraction

\subsection{Flexural Load and Mid-Span Deflection}

The flexural load is the maximum load the composite can bear before fracture during flexure/ bend test. Figure 2 depicts the results graphically. The samples with $4 \%$ and $2 \%$ fibre mass fractions showed excellent ability to withstand the highest load before fracture with values of $23.277 \mathrm{~N}$ and $21.147 \mathrm{~N}$ respectively while samples with fibre mass fractions of $6 \%, 8 \%, 0 \%$ (control) and $10 \%$ follow in that order with decreasing load sustainability.

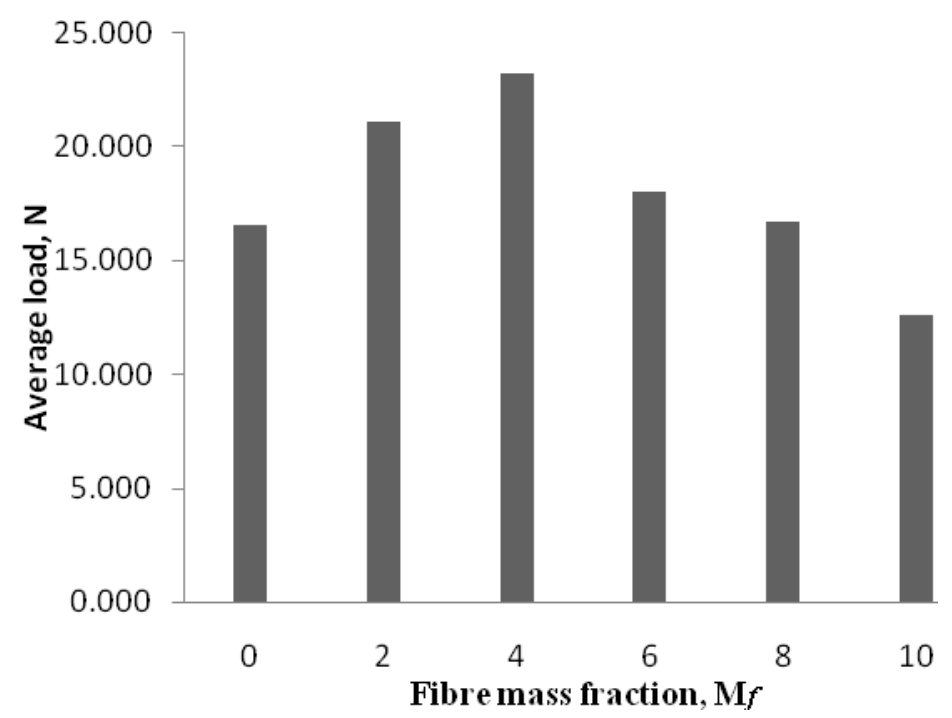

Figure 2: Plot of Average Load against Fibre Mass Fraction 
Figure 3 shows the mid-span deflection which is a measure of both the ductility and toughness of each of the samples. The samples with $4 \%$ fibre mass fraction showed the greatest deflection with value of $25 \mathrm{~mm}$ signifying that it possessed the highest ductility. The control had the lowest value of $9 \mathrm{~mm}$ showing that it had a poor ductility, and hence, most brittle of all the samples.

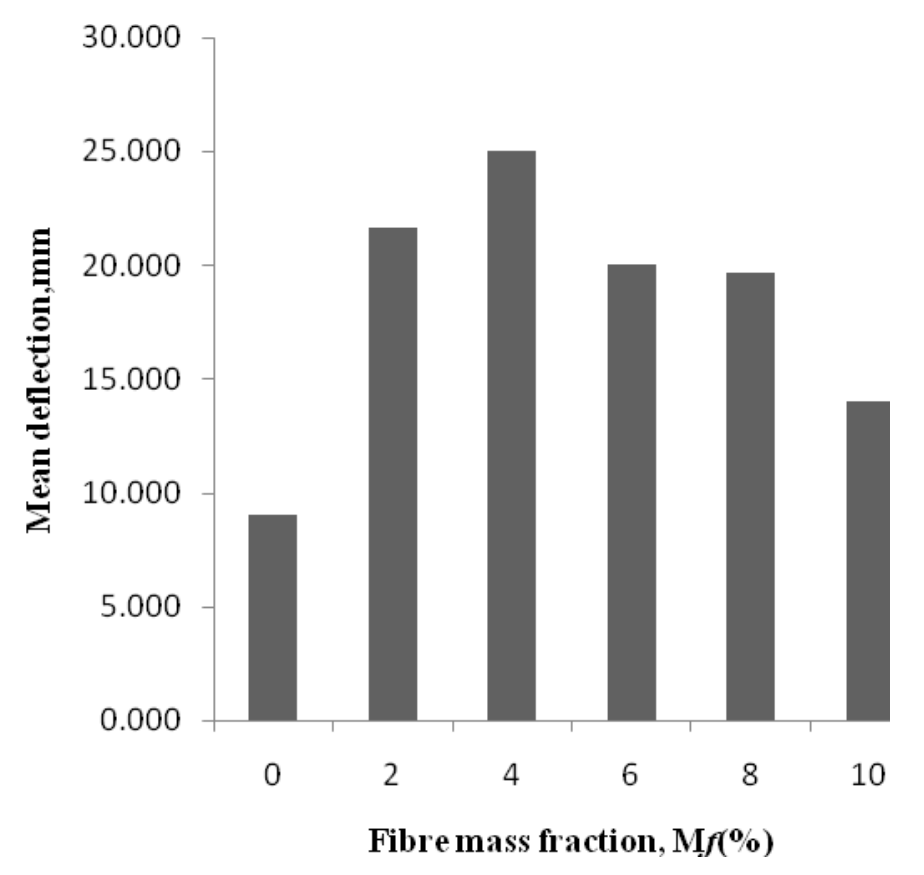

Figure 3: Plot of Mean Deflection against Fibre Mass Fraction

\subsection{Water Absorptivity Test Results}

Figure 4 depicts this result graphically. From the results obtained, the control sample $\left(0 \% \mathrm{M}_{\mathrm{f}}\right)$ had the lowest percentage mean water absorptivity with a value of $52.519 \%$. This was followed by the samples with $4 \%$ fibre mass fraction with a value of $65.783 \%$. Samples with $2 \%, 8 \%$ and $6 \%$ fibre mass fractions also followed in an ascending order of water absorptivity while the $10 \%$ fibre mass fraction absorbed the highest quantity of water. 


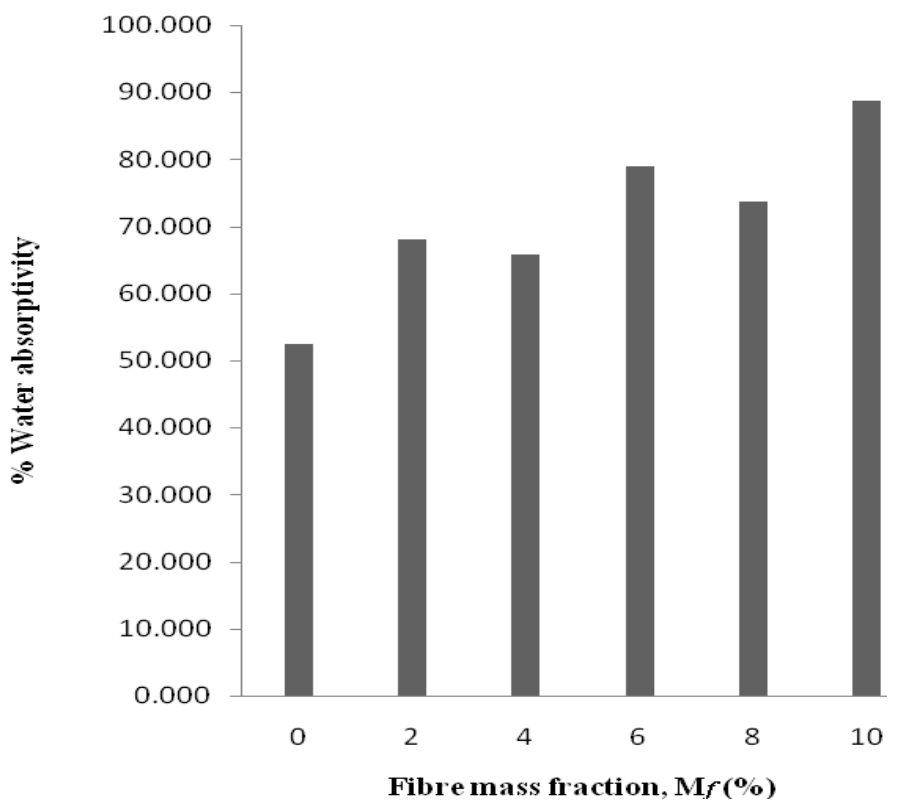

Figure 4: Plot of PercentageWater Absorptivity against Fibre Mass Fraction

\section{CONCLUSION}

The results and analyses of the data obtained from this research work show that:

i. Randomly distributed natural vegetable fibres can be used to improve the flexural strength of flat cement composite sheets.

ii. The flexural strength and load of the samples tested increased with increasing fibre mass fraction included in the matrix, reaching a maximum at $4 \%$. A decline was observed in these two properties from fibre mass fraction of $6 \%$ to $10 \%$. Therefore, the optimum fibre mass fraction required for strengthening using natural sponge fibre is $4 \%$.

iii. The control sample showed the least response to water absorptivity followed by the samples with $4 \%$ fibre mass fraction. All other fibre mass fraction samples absorbed more than half their dry weights of water. This could possibly be due to the presence of air spaces and voids as a result of the increasing fibre content included in the matrix and increasing difficulty experienced during mixing with the addition of upwards of $6 \%$ fibre in the matrix.

This research work has confirmed the excellent suitability and performance of cement composites reinforced with natural sponge fibres (Acanthus montanus). Strength and ductility showed better improvement at the optimum fibre mass fraction of $4 \%$. 


\section{REFERENCES}

1 Swamy, R.N. (1990), Vegetable Fibre Reinforced Cement Composites- A False Dream or a Potential Reality, Proceedings of Second International RILEM Symposium ,1st edition, Chapman \& Hall, London (ed. H.S Sobral), pp. 3-8.

2 Benjamin ,C.T. (1990), Fabrication and Performance of Natural Fiber-Reinforced Composite Materials”, 35th. International SAMPE Symposium, pp.970-978.

3 Al-Qureshi H.A .(1999), The Use of Banana Fibre Reinforced Composites for the Development of a Truck Body, Second International Wood and Natural Fibre Composites Symposium, Kassel/Germany, pp.1-8.

4 Brandt, A.M. (1995), Cement Based Composites: Materials, Mechanical Properties and Performance, 1st edition, Chapman and Hall, London, pp. 5-60, 77-97.

5 Soroushian, P and Mankunte, S (1990), High Performance Fibre Reinforced Cement Composites, (eds. H.W. Reinhardt and A.E. Naaman), E and FN Son, London, pp. 8499.

6 Hussin, M.W. and Zakaria, F. (1990), Prospects For Coconut Fibre-Reinforced Thin Cement Sheet in the Malaysian Construction Industry, Proceedings of the Second International RILEM Symposium,1st edition, Chapman \& Hall, London (ed. H.S Sobral), pp. 77-80.

$7 \quad$ Lasisi, F and Ogunjimi, B. (1984), Source and Mix Proportions as Factors in Characteristic Strength of Laterized Concrete, International Journal for Development Technology, 2:3, pp. 8-13. 